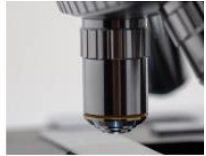

\title{
Attention Deficit Hyperactivity Disorder (ADHD)
}

\author{
Maria Alyce de Lima Alves'; Maria Eduarda Ferreira da Silva ${ }^{\mathbf{1}}$; Mayara Madalena de Souza'; \\ Ryan Rodrigo da Silva Oliveira ${ }^{1 *}$; Yasmin Maria da Silva França ${ }^{1}$
}

1 Department of Psychology, Center for Humanities, University Center of Vitória de Santo Antão (UNIVISA), Vitória de Santo Antão, Brazil E-mail adresse: alyce_alves@yahoo.com (Maria Alyce de Lima Alves), eduardaferreiradsilva@gmail.com (Maria Eduarda Ferreira da Silva), mayarasouza20181@hotmail.com (Mayara Madalena de Souza), ryanoliverbelarmino@icloud.com (Ryan Rodrigo da Silva Oliveira), yasminfranca1001@gmail.com (Yasmin Maria da Silva França)

*Corresponding author

\section{To cite this article:}

Alves, M.A.L.; Silva, M.E.F.; Souza, M.M; Oliveira, R.R.S.; França, Y.M.S. Attention Deficit Hyperactivity Disorder (ADHD). International Journal of Sciences. Vol. 1, No. 1, 2021, pp. 5-10.

Received: 01 29, 2021; Accepted: 01 29, 2021; Published: 02 02, 2021

\begin{abstract}
The current study made us conduct a bibliographical research with the objective of understanding more about the importance of treatment, difficulties and what is attention deficit hyperactivity disorder (ADHD), and the social environment's action on who has this problem, emphasizing the therapeutic medicinal process through the individual with the disorder. A research was conducted with questions related to this disorder to get an idea of people's knowledge and lead them to clarify their doubts about this dysfunction. In the work, the medical and psychotherapeutic treatment, quality of life in education and in the social environment, their difficulties and prejudices with people with ADHD, and how important their insertion in society in a very inclusive way was emphasized.
\end{abstract}

Keywords: Attention Deficit Hyperactivity Disorder; ADHD; Treatments; SPSS

\section{Introduction}

Attention Deficit Hyperactivity Disorder (ADHD) is a neurological problem of genetic cause marked by heredity, which usually manifests during childhood from seven years of age and thus accompany the subject throughout his life, having in the constitution of his behavior aggression, hyperactivity, inattention, impulsivity, restlessness, among others, but of course, manifesting in different ways according to the human being. (Sundays \& Risso, 2000) This disorder, despite not having a cure, tends to decrease with age and with the correct treatment, both psychotherapy and medication, thus enabling the individual to live his life so that this problem does not hinder him/her in his/her tasks.

Young people who have the hyperactive disorder, are reckless and impulsive often, thus having marked their relationships with other individuals with an absence of social inhibition and lack of caution. According to Rohde and Benczik (1999), the hyperactive disorder is a mental health problem that has three basic characteristics: distraction, agitation and impulsivity. In adults, on the other hand, it persists in their daily life at work, in which it manifests itself as forgetfulness of things, it remains inattentive to boring, repetitive works, has as its pattern of impulsivity the difficulty of waiting and sustains the behavior of constant movement because of hyperactivity.
Finding students with ADHD in the school environment has become increasingly frequent, these people are most often confused with individuals who have bad behavior and a certain resistance to the guidance of teachers. According to the work of Reis published in 2011, once ADHD is diagnosed, this student should be considered as a child with special educational needs, so that he has guaranteed the same opportunities to learn that other classmates, thus, some adaptations will be necessary in order to reduce the occurrence of undesirable behaviors that may impair his pedagogical progress.

Thus, although educators do not have sufficient theoretical knowledge and property about ADHD, their practice in the school environment allows the analysis, observation and development of hypotheses for the adaptation of their method so that students who have the deficit are respected and included in the classroom.

ADHD, characterized by its symptoms, can be classified into four types:

- Inattentive type: Makes mistakes due to lack of care, has difficulty in maintaining attention, disorganized and avoids activities that require maintaining a prolonged focus.

- Hyperactive/impulsive type: Restlessness, there is difficulty in sitting and participating in silent activities, because it speaks excessively and intrudes in conversations.

- Combined type: This is when the individual has 
characteristics of the inattentive and hyperactive/impulsive type.

- Non-specific type: This is when a conclusion is not reached in relation to the diagnosis, however, it still has symptoms that unbalance its daily routine. (APA, 2002; Rappley, 2005)

When we perceive this dysfunction in someone, especially if it is in our family or friends, care is needed, besides being understandable the lack of patience with the individual, it is indispensable that one has understanding and that does not exaggeate in criticism, because it can lead to a child or those who have the disorder to retract and begin to present greatly diminished self-esteem, or that aggressive and impulsive behaviors be initiated (Silva, 2003). Soon after receiving the diagnosis of $\mathrm{ADHD}$, patients often receive guidance on drug treatment, in which methylphenhydrate (ritalin) would be used and which has a very significant improvement.

In Brazil, the drug mentioned above is recognized for its better efficiency, and is prescribed and monitored by the doctor, there is evidence that the drug will rarely cause dependence, and its effect lasts about $4 / 5$ hours, and most of the times recommended to persist with treatment when symptoms manifest again. This drug, in $70 \%$ of cases, greatly decreases ADHD symptoms, but when it has no positive effects, antidepressants are used that are mostly not recommended. (Mattos, 2001; Silva, 2003; Klein \& Abikoff, 1997).

Psychotherapeutic treatment is recommended when there are comorbidities or not, such as depressive disorder or conduct in the individual, and there are also secondary problems such as school, social or home issues that should be referred quickly. In the case of when there are no comorbidities, but the subject presents a certain clinically significant suffering, it should also be referred. Although the person does not demand this treatment, every case of ADHD requires guidance, both to understand the behavior of those who have the disorder and to facilitate social interaction and create ways to prevent future problems, in addition to identifying certain central points in the person, such as lack of knowledge about the disorder and thus thinking that it is incapable or not intelligent, and to make it take a transformative view of itself (Doyle, 2006; Rostain and Ramsay, 2006).

\section{Methodology}

There was an online questionnaire, due to the pandemic of Covid-19, through the Google Forms platform and made available on networks such as WhatsApp and Instagram with 20 questions and in order to be aware of people's knowledge about the topic OF ADHD. Finally, obtaining this information, the Software SPSS 22.0 was used to obtain graphs used for this research, in addition to analyzing the results of these questions.
It is also of paramount importance to point out that the research was conducted with people of different ages, being thus collected in general and impartially, with this were generated several results about attention deficit hyperactivity disorder, where they will be elapsed throughout the article.

\section{Results and Discussion}

The survey obtained a total of eighty-three responses, with an index of $73.5 \%$ of the participants corresponding to young people between 15 and 20 years old, and $26.5 \%$ older than 21 years.

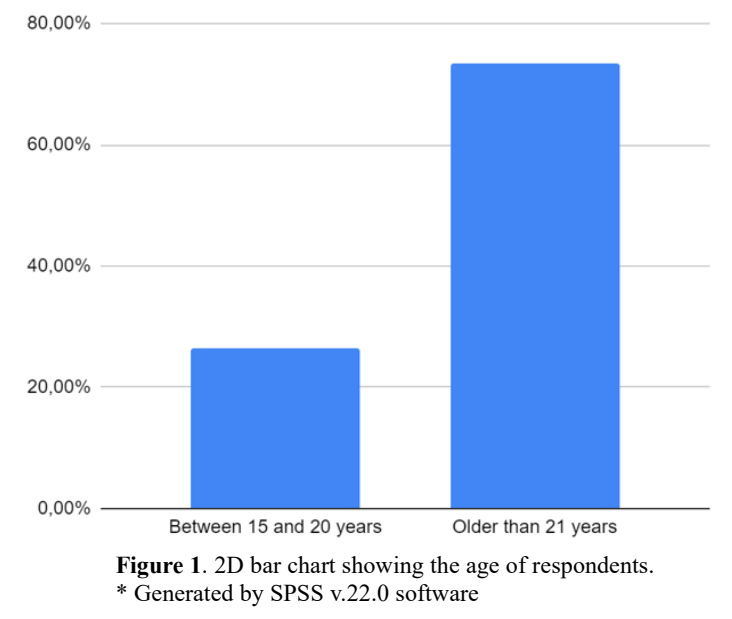

Of those willing to answer, $77.1 \%$ were female and only 19 of them did not have any kind of knowledge about Attention Deficit Hyperactivity Disorder.

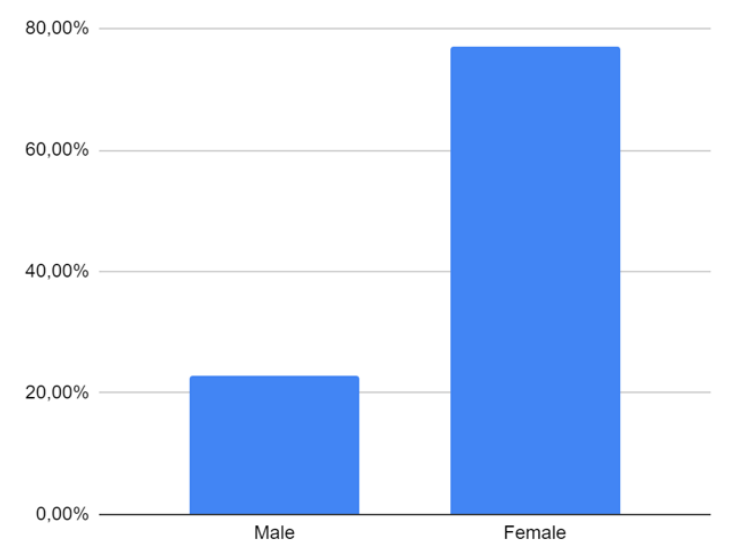

Figure 2. 2D bar graph showing the sex of respondents. * Generated by SPSS v.22.0 software

Of the participants who answered the questionnaire, 59\% stated that they knew someone with ADHD. 


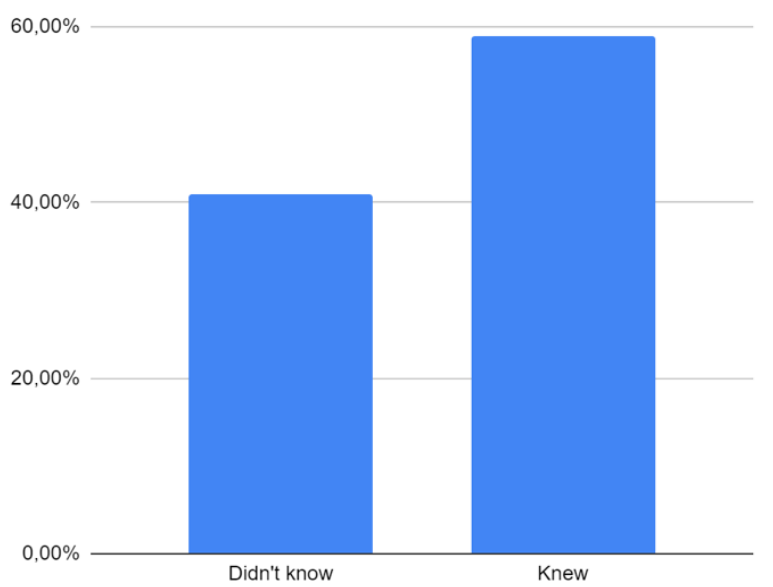

Figure 3. 2D bar chart that shows the answer to the question: Do you know anyone with ADHD? * Generated by SPSS v.22.0

When asked about the treatment for children without the use of medications, $63.9 \%$ believe that it is possible. $80,00 \%$

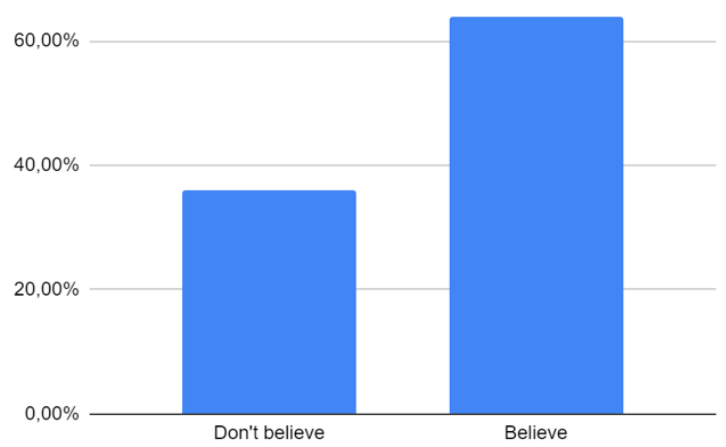

Figure 4. 2D bar chart that shows the answer to the question: Do you think it is possible to treat a child without the use of medications? * Generated by SPSS v.22.0

Regarding the performance of the social life of a child with attention deficit hyperactivity disorder and a child who does not have it, $72.3 \%$ believe that yes, the child's life is impaired by ADHD.

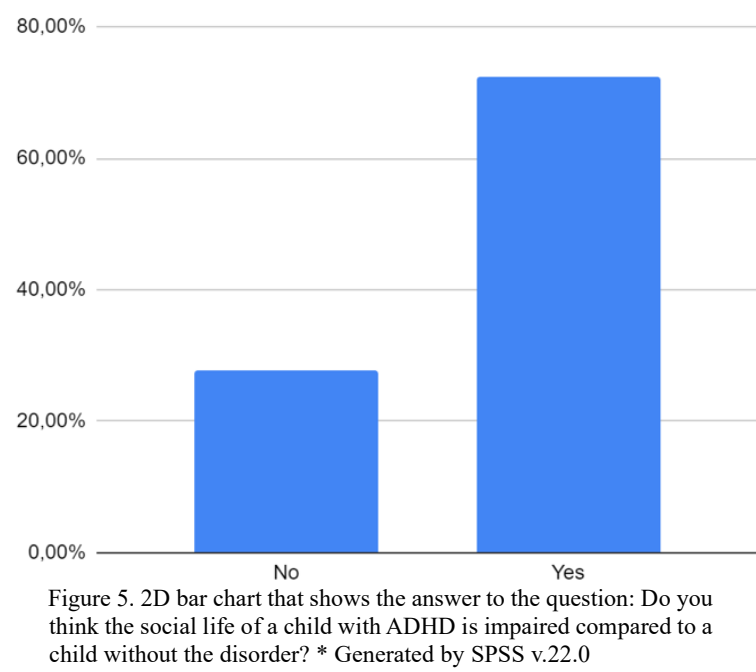

Regarding knowing how to know a teenager with the disorder, $59 \%$ of the participants stated that they could not recognize it.

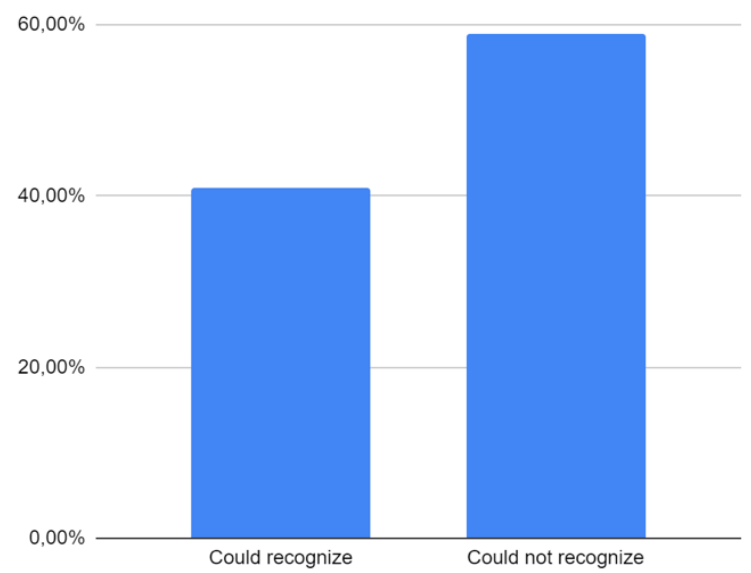

Figure 6. 2D bar chart that shows the answer to the question: Would you know how to recognize a teenager with ADHD? * Generated by SPSS v.22.0

And about recognizing ADHD behaviors, 56 people said they were capable of recognizing.

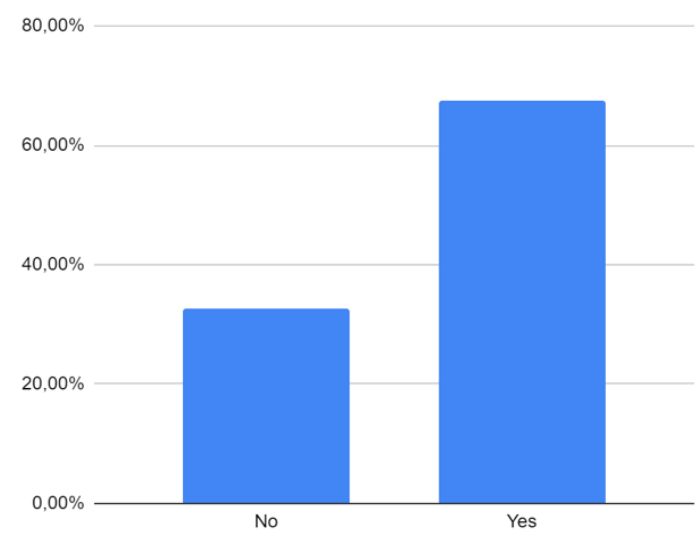

Figure 7. 2D bar chart that shows the answer to the question: Would you know how to detect some ADHD behaviors? * Generated by SPSS v. 22.0

ADHD is divided into 3 parts, on this aspect, $30.1 \%$ were unaware.

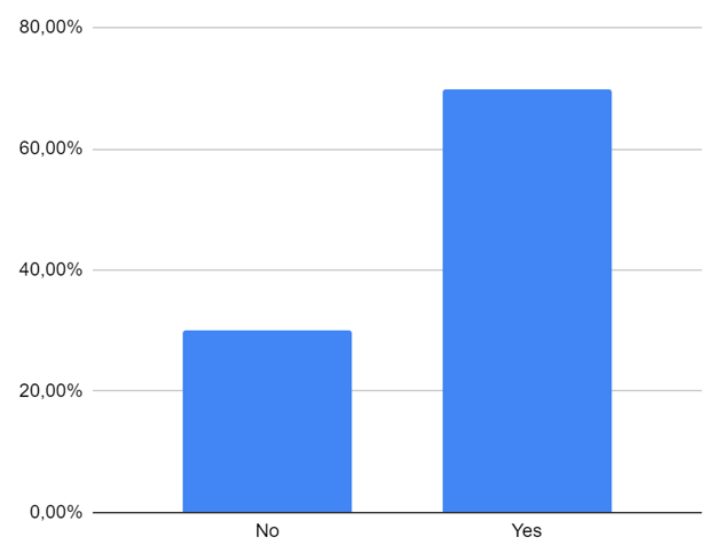

Figure 8. 2D bar chart that shows the answer to the question: Did you know that ADHD can be classified as to the severity of it in Mild, Moderate, and Severe? * Generated by SPSS v.22.0.

When asked if they knew the disorder was a life condition and not a disease, 40 people were aware of it. 
$60,00 \%$

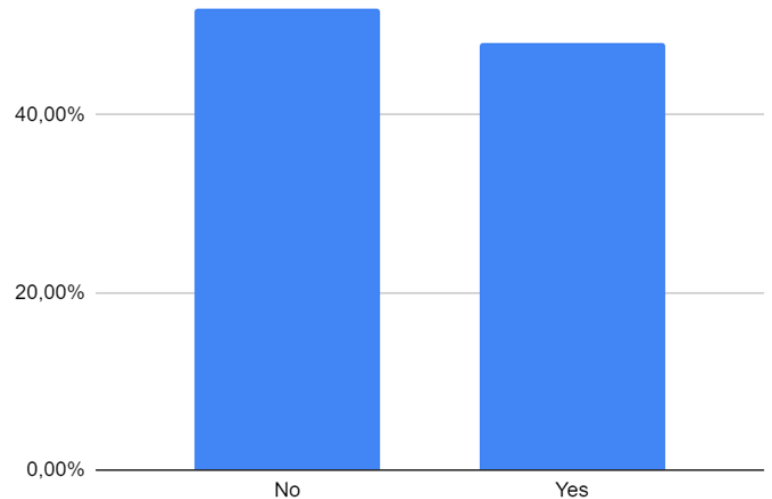

Figure 9. 2D bar chart that shows the answer to the question: Did you know that ADHD is not a disease but a living condition? * Generated by SPSS v.22.0.

However, at the end of the interview, they were asked if they knew of the existence of effective treatments in most cases, $72.3 \%$ knew of the proof of the efficacy of the treatment.

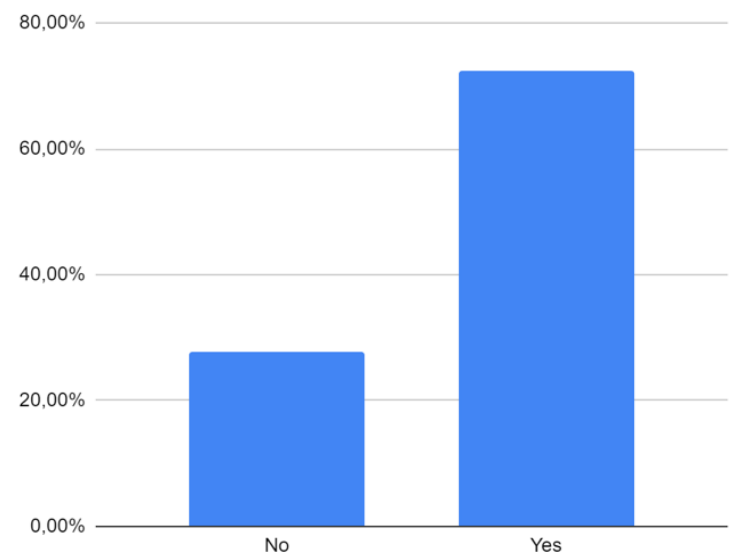

Figure 10. 2D bar chart that shows the answer to the question: Did you know that for ADHD has effective treatments and that in the vast majority of cases works? ${ }^{*}$ Generated by SPSS v.22.0.

Based on some of the questions and answers asked in our questionnaire, we can realize how many people still do not know attention deficit hyperactivity disorder, and in some cases because they do not know it, they end up not giving due attention to a child or adolescent who has the same doing so, with which she lives with it without knowing and not knowing the treatment for his life condition. It is of great importance that parents can know more about ADHD and its symptoms, so that they can look at the way their child is acting, so that they can diagnose and help by making their child perform better in their social life. After collecting the answers to the questionnaire, it was clear that individuals as a whole have divergent opinions on the subject, which most of them have the knowledge of what the disorder is about, in opposition the vast majority do not know it meaning or even do not have the ability to identify it.

\section{Conclusions}

With this article, it is concluded stating that: ADHD is a disorder that can be treated and controlled, it can limit the individual, however, due to treatment, it can decrease symptoms, thus facilitating their coexistence in the social environment. Fortunately, most of the people interviewed by us are aware of what the disorder is about, and recognize that it is not a problem that can exclude the individual from the social body.

\section{Acknowledgements}

We thank our advisor Prof. Pierre Teodósio Felix for their willingness and willingness to help us, restraining our doubts when we needed to.

\section{References}

[1] AMERICAN PSYCHIATRY ASSOCIATION (2002). Manual Diagnóstico Estatístico de Transtornos Mentais. ( $4^{\mathrm{a}}$ ed.). Porto Alegre: Artmed.

[2] ANDRADE, E. R., \& SCHEUER, C. (2004). Análise da eficácia do metilfenidrato usando a versão abreviada do questionário de Conners em transtorno de déficit de atenção/hiperatividade. Arq Neupsiquiatr, 62 (I), 81-85.

[3] DOMINGOS, N. A. M., RISSO, K. R. (2000). O transtorno de déficit de atenção e a hiperatividade infantil. Em E. F. M. Silvares (Org.), Estudos de caso em psicologia clínica comportamental infantil (pp. 63-83). Campinas: Papirus.

[4] DOYLE, B. B. (2006) Understanding and Treating Adults with Attention Deficit Hyperactivity Disorder. Washington: American Psychiatric Publishing.

[5] KLEIN, R. G., \& ABIKOFF, H. (1997). Behavior therapy and methylphenidate in the treatment of children with ADHD. Journal of Attention Disorder, 2, 89-114.

[6] MATTOS, P. (2001). No mundo da lua: Perguntas e respostas sobre transtorno de déficit de atenção com hiperatividade em crianças, adolescentes e adultos. São Paulo: Lemos Editorial.

[7] RAPPLEY, M. D. (2005). Attecion-deficit-hyperactivity disorder. NEngl J Med, 352 (2), 165-173.

[8] ROHDlE, L. A. P. \& BENCZIK, E. B. P. Transtorno de atenção/hiperatividade: o que é?: Como ajudar? Ed. Artes Médicas Sul, 1999.

[9] ROSTAIN, L. A. \& RAMSAY, J. R. (2006). A Combined Treatment Approach for Adults With ADHD - Results of an Open Study of 43 Patients. Journal of Attention Disorders, 10 (2), 150-159.

[10] SILVA, A. B. B. (2003). Mentes inquietas: entendendo melhor o mundo das pessoas distraídas, impulsivas e hiperativas. Rio de Janeiro: Napedes. 